\title{
Possible Tensions Between Individual Needs and Collective Treatment Methods for Substance Use Disorders and Addiction
}

\section{Yngve Herikstad*}

Faculty of Health and Welfare Sciences

Østfold University College

Email: yngve.herikstad@hiof.no

*corresponding author

\section{Haakon Tuman Falck}

Faculty of Health and Welfare Sciences

Østfold University College

\section{Mia Kristin Hoel}

Faculty of Health and Welfare Sciences

Østfold University College

\section{Anders Dechsling}

Faculty of Health and Welfare Sciences

Faculty of Education

Østfold University College

Email: anders.dechsling@hiof.no

\begin{abstract}
The inpatient collective treatment model has strong historical roots in the treatment of people with substance use disorders in Norway. It focusses on safe and drug-free environments that support growth and development in individuals admitted for treatment emphasising the community as method idea. However, little is known about how flexible such treatment approaches are when adjusting to individual treatment needs. Here, we
\end{abstract}


explore how such individual treatment needs are safeguarded within the framework of collective inpatient institutional settings by interviewing treatment staff members who hold a bachelor's degree in social or health sciences $(N=5)$. The focus of our analysis is on exploring the possible challenges that may occur as a result of competing conflicts between individualised person-centred treatments in institutional settings that aim to build strong communities. Our findings here are summarised in three major themes: (a) individual treatment needs face possible neglect with strong adherence to the treatment programme, (b) too rigid an interpretation of community as method may lead to attributional errors and a possible rejection of the client and (c) the collective paradigm faces important challenges regarding individuals with cognitive deficits. To the best of our knowledge, this study is the first to shed light on the tensions regarding individualised person-centred treatment arrangements within the collective treatment paradigm. Thus, our findings may provide increased awareness and better understanding of this problem and should inform future research questions, as well as professional education and clinical practices. Future research should focus on how to balance individualised treatment within the framework of inpatient collective treatment. In addition, important clinical implications relate to how such individualised person-centred treatment may contribute to better treatment quality and outcomes in programmes applying the community as method idea.

Keywords: substance use disorders, collective treatment, inpatient treatment, community as method, individual treatment, cognitive deficits, therapeutic alliance

\section{Introduction}

The treatment of people with substance use disorders has different designs in the Norwegian healthcare system. Since 2004, the responsibility for the treatment of various substance use disorders has been transferred from the local municipalities to the centralised and specialised healthcare systems provided by the state. A new sector called TSB (a Norwegian abbreviation for Transdisciplinary Specialised Treatment) within specialised state healthcare now provides integrated specialised treatment to people with substance use disorders (Ose \& Pettersen, 2014; Ravndal, 2007). TSB has different layers of intervention, including acute detoxification, outpatient treatment, short- and long-term inpatient treatment and post-treatment care of various lengths. Among these, long-term inpatient treatment is by far the largest, accounting for 
around $80 \%$ of TSB's total costs. Further, long-term inpatient treatment within TSB consists of both public and private institutions, where private institutions provide around $60 \%$ of the total number of treatment days/nights. The institutions are designed in various ways, and within TSB, people with substance use disorders can be offered different kinds of treatments, such as therapeutic community models or inpatient collective treatment with different kinds of aftercare arrangements (Ose \& Pettersen, 2014; Ravndal, 2007; Steiro et al., 2009).

The inpatient collective treatment model has strong roots in the treatment of people with substance use disorders in Norway, especially for adolescents but also for adults. The collective paradigm, as we label it here, places a strong emphasis on the potential of the collective group as a key treatment component and has its roots in the Hassala movement of the 1970s in Sweden (Kolltveit \& Lange-Nielsen, 2013). Traditionally, the Norwegian collective treatment model has had a strong ideological basis of implementing methods of social pedagogy and focussing on therapeutic relationships and the institutional community as a basic method. Further, the collective treatment model's ideology comprises the basic assumption that the building of relationships with co-clients and treatment staff in a safe environment and establishing a strong sense of affiliation with the institutional community will strongly influence growth and development (Kristoffersen et al., 2011; Ravndal, 2007). Thus, although the collective treatment approach is mainly a Scandinavian phenomenon, it is influenced by what therapeutic communities label community as method (De Leon, 2000; De Leon \& Wexler, 2009; Kolltveit \& Lange-Nielsen, 2013; National Institute on Drug Abuse [NIDA], 2015). People living together in a drug-free environment is considered a key component. De Leon (2000) emphasised that living in such therapeutic communities, together with other people who engage in own and others' change processes, is an important factor concerning their effort to change their destructive patterns of substance abuse and identity building. 
Mutuality in help processes is a key feature, and the therapeutic environment that is being shaped in such arrangements provides multiple opportunities for changing one's lifestyle and identity through various activities, social interactions, bonding, support and so forth (NIDA, 2015). The collective treatment model also emphasises the community as method idea by arranging the environment so that the treatment staff live with the clients, participating in the daily lives and routines of the institution (Ravndal, 2007).

One challenge for the concept of community as method may come from an emphasis on how clients adjust to the institutional framework and specific social rules of conduct in the institution. If the goal is to build a prosocial environment that represents strong affiliation and allows clients to experience safety and support, adherence to the institutional rules of conduct is important. However, a lack of flexibility in adherence could also be characterised as a pitfall. Research on treatment outcome predictors suggests that rigidity of treatment components may attenuate alliance and increase resistance in clients (Wampold, 2015). Further, resistance and a lack of therapeutic alliance may represent challenges to the client's acceptance of treatment. For instance, Chen et al. (2015) found that young people who had dropped out of therapeutic community treatment generally experienced what the authors labelled antagonistic interactions between adolescents and staff. The informants described unjustified punishment and rigidity concerning the institutional rules and a lack of sensitivity from staff members regarding their situation. This resulted in the adolescents engaging in even more resistance, which evoked further reactions and so forth, and finally, their dropping out of treatment (Chen et al., 2015).

The antagonistic interactions described above are in accordance with what Brorson et al. (2013) found in their systematic review regarding important risk factors for people with substance use disorders who drop out of treatment. In addition to patient-related risk factors, such as cognitive deficits, personality 
disorders and young age, they identified therapeutic alliance as a crucial factor (Brorson et al., 2013). Thus, a rigid emphasis on the community as method in a collective treatment model may face challenges regarding important treatment principles (i.e. therapeutic alliance) in the treatment of people with substance use disorders and other patient groups.

Both domestic and international guidelines state that treatment efforts and interventions should be arranged according to the client's current health situation and thus be individually assessed, arranged and adjusted (Helsedirektoratet, 2011, 2017; NIDA, 2014). For instance, NIDA in the United States points out that treatment should be individually tailored to the person's unique needs, and this tailoring should address the person as a whole rather than just focussing on substance use issues (NIDA, 2014, pp. 9-10). Thus, treatment plans and the therapeutic arrangement of the environment to facilitate change should be adjusted from the starting point of identified needs on an individual level. For instance, by using national data from a range of therapeutic communities in the United States $(n=345)$, Dye et al. (2012) found that a great portion of the therapeutic communities in the sample admitted clients with various co-occurring disorders. In addition, approximately $50 \%$ of the therapeutic communities report that they provide integrated care or treatment. This is an interesting finding, and it shows how the therapeutic communities are adapting and possibly evolving towards a more individual treatment position through a greater use of professionals and various therapeutic interventions within the therapeutic community model (i.e. psychotherapy) and decreasing the confrontational aspect traditionally emphasised in such treatment (Dye et al., 2012). In other words, the increased focus on and awareness of individual treatment needs call for an increased understanding that such needs require individual treatment arrangements. However, this balancing between important treatment components (i.e. community as method) and individual adjustments may be demanding. For instance, the client's need for individual adjustments in 
the treatment may stand in direct opposition to the programme's expectations for the client regarding participation in activities, group treatments and so on, and this may represent important distortions to the institutional community that must be addressed.

The complex and problematic co-occurrence of various mental health challenges and substance use problems represents multiple and complex challenges regarding treatment efforts. Such dual and complex recovery issues are addressed by Ness et al. (2014). In their review, they identify important facilitators and barriers in recovery processes, describing the lack of tailored help as one such important barrier in four out of seven identified studies. Thus, how such complex issues are identified and met by professionals on an individual level, suggesting an understanding of the person's life situation and their need for individualised and tailored help, is considered important in recovery processes (Ness et al., 2014). Recovery is seen as an individual and dynamic process (Slade et al., 2012), and an important feature of the treatment effort is that the treatment or treatment provider should adapt to the person. Traditionally, in the treatment of people with substance use disorders and mental illnesses, the opposite has been the case, where such treatment has adopted the view that the client should adapt to the programme (Slade, 2009).

The conflict or trade-off between individualised treatment and the benefits of community as method represents a frequently discussed, yet not systematically researched, problem field for practitioners. For instance, making important facilitations to individualise and tailor treatment will entail challenges in preserving the community as method idea. This paper aims to contribute to a better understanding of this problem field by exploring the possible tension between the collective treatment model's emphasis on the community as method and individual treatment needs, how such needs are met and safeguarded in the treatment of the individual in proportion to the institutional 
community and what kind of challenges treatment staff face in cases where individual treatment needs must be handled with intervention efforts other than those the collective treatment model posits.

\section{Method}

\section{Participants}

We recruited five informants from two private institutions in Norway that provide inpatient collective treatment for youth with drug abuse behaviour. The informants had different backgrounds respecting both education and experience and different positions in their respective institutions. Three informants had previously established professional relations with the interviewers (Authors 2 and 3), while the other two had no such relations.

\section{Inclusion and Exclusion Criteria}

To qualify for the study, the informants were required to be working with clients in institutions providing collective treatment. In addition, they needed to have a bachelor's degree in health and social science and have worked in their institutions for more than a year. We emphasised variations in the group of informants regarding educational and professional background, sex, and position.

\section{Data collection and Analysis}

We interviewed the informants using a semi-structured interview procedure. The themes that made up the framework of the interview covered important areas of topics relevant to the research question. The interviews aimed to address personal aspects regarding education and experience, as well as organisational issues. They covered important aspects regarding strengths and weaknesses in the collective treatment's emphasis on the group as method and how individualised treatment issues are safeguarded. In addition, issues regarding 
how the treatment focussed on the prevention of individual-level dropout were addressed. Further, the semi-structured interview procedure allowed for indepth exploration of important ethical normative aspects. Issues regarding outcomes were also of interest. The resulting framework comprised the interview guide, which we tested with a pilot and evaluated prior to the first interview.

The interviews were conducted in offices at the institutions, which served as familiar settings for the informants. The second and third authors were present in all the interviews but alternated their roles in the different interviews. The interviewer asked and followed up the questions and conversation while the other author took notes. We used an analogue tape recorder throughout the interviews, which was approved by all the informants.

The second and third authors transcribed the data from the tape recorder, while the first and last authors analysed the data thematically according to the guidance provided by Braun and Clarke (2006). The interviews were conducted in Norwegian. The quotes provided in the results and discussion section were translated by the first and last authors.

To reduce the risk of a biased data analysis, we separated the collection and analysis of the data between different authors. To ensure validity and reduce the risk of bias in the analysis process, we applied Braun and Clarke's (2006) guidance for conducting thematic analysis of qualitative data.

\section{Ethical Considerations}

The project (including tape recording) was approved by the Norwegian Centre for Research Data (NSD). The data were stored safely, and we followed both the national authority's and local institution's guidelines. All participants read a 
letter of information and signed the written consent form prior to participation. The interview guide did not contain questions that might elicit negative emotions in the participants; however, they were informed that they could exit the interview at any time without giving a reason and that it would not affect them negatively regarding their relation to the interviewers.

\section{Results and Discussion}

The thematic analysis resulted in the three following themes: (a) individual needs versus the treatment programme enshrined in the institutional framework, (b) individual lack of motivation and utilisation of treatment efforts and (c) cognitive deficits and treatment methods. We present and discuss the results within these themes chronologically.

\section{Individual Needs Versus the Treatment Programme Enshrined in the Institutional Framework}

A central principle in professional health and social services is that the interventions and facilitations of such services should be based on the individual needs of the client (Helsedirektoratet, 2011, 2017; NIDA, 2014). This means that, for people with substance use disorders, careful and integrated individual assessment of multiple, important life areas must occur to identify important and specific treatment needs on a personal level, both prior to and upon admission to treatment. This is conducted to ensure that necessary professional help is provided for the individual. However, when committing to treatment in an inpatient institutional setting, the treatment programme will often be enshrined in the institutional framework. This would be particularly important in an inpatient collective treatment model, where prioritised treatment activities have their basis in the regular routines of the day, such as mandatory group activities, group treatment, phase-based treatment progression and affiliation with the group as 
a key feature of the treatment ideology (Kolltveit \& Lange-Nielsen, 2013; Ravndal, 2007).

Our findings suggest that there is a tension between individual facilitation or design of adequate treatment and the institutional treatment programme implemented for all admitted clients, where

the adolescent didn't manage to tune into a group. Didn't manage to utilise the group therapy, and then our challenge regarding the individual needs becomes so big that we're not able to help the person here.

It is important to address such individual issues, but at the same time, such a narrow focus can indeed represent a threat to the integrity of the treatment ideology and programme. One participant highlighted:

If it is only the group [focus], we lose the individual [focus], and if it is too much focus on the individual, then . . . we don't lose the group, but in a way we lose a lot of the instruments in running a group, thus this balancing act ... to be able to see both sides, is very difficult, and my experience probably is that we're more likely to preserve the group rather than the individual [focus].

This tension is critical when it comes to the individual client that displays needs that the institutional setting or programme does not properly meet. Certain hallmarks regarding the group as a whole concern knowledge that is clearly important to include in the structure of the treatment programme. The understanding of community as method means that the whole group provides safe and drug-free environments that facilitate strong and supportive relationships (De Leon, 2000; De Leon \& Wexler, 2009; Kristoffersen et al., 2011; Ravndal, 2007). However, people with substance use disorders are a heterogeneous group, displaying a variety of symptoms and often co-occurring 
disorders (Dye et al., 2012). This requires not only an emphasis on group hallmarks but also the dynamics and interaction of individual factors in relation to treatment factors. Hence, the issues regarding attrition from treatment may also be considered a hallmark in the treatment of substance use disorders. For instance, in their systematic review, Brorson et al. (2013) found that dropping out of treatment is more common than completion is, and the variables that affect clients dropping out of treatment must be analysed from an individual perspective. Specifically, Brorsson et al. (2013) found that cognitive deficits, low treatment alliance, personality disorder and young age are important risk factors for dropping out of treatment, suggesting that careful assessment and monitoring of the therapeutic alliance are key factors in preventing such dropout.

Our findings suggest that collective treatment involves challenges regarding how complex individual needs are handled in the institution. This often results in action that refers to other, more suitable admissions that better fit the individual rather than prioritising treatment interventions in the institutional setting in which the person displays problems. In some cases, these challenges can result in what Chen et al. (2015) labelled an antagonistic relationship:

He has destroyed enough and now he has to leave, now he should pack his bag-and that becomes very hard. ... Mhm, ... and I have also been a part of that.

\section{Individual Lack of Motivation and Utilisation of Treatment Efforts}

The staff in an inpatient treatment programme are naturally trained in how group affiliation and the structure of phase-based treatment progression may represent important motivational factors for the clients. They are also aware of how the group and co-clients can provide important support and affirmation to the single client who struggles. Our participants addressed this by focussing on co-living therapeutic organisation and group affiliation as important aspects 
regarding the shaping of relationships and supportive environments in cooperation with the clients. One interviewee referred to 'support. The group is doing well in supporting the others, and ... yes. I think the institutional community, to be able to recognise oneself, support, sharing of experiences'; such statements were commonly made by the participants. How the institutional community can be an important tool in helping others persevere in the treatment is obviously an important feature of the basic therapeutic assumption. However, our interpretation suggests that the treatment ideology, as well as the integrity and preservation of the treatment programme, may also present a risk of neglecting critical individual issues that need special attention. The belief in the treatment programme's strength and its ability to help people with substance use disorders change their lives may also represent a possibility to make fundamental attribution errors (Ross, 1977). This happens when situational factors are neglected or underestimated and there is too much focus on inner factors and individual traits in causal inferences about behaviour. Lack of motivation or utilisation of treatment efforts, for instance, will easily be assigned to the client and not the environmental factors of the treatment programme:

It is like professional judgements about utilisation of the treatment, about what we do here, because our model is kind of set, so to speak. But it happens that we admit clients that are too ill to be here, and then we have to take action. But as long as they are still here waiting to be admitted somewhere else, we have to try our best to make individual adjustments, not press our programme upon the person. I think we're pretty good at that.

This statement may illustrate our point regarding attribution. Other, similar statements are present in our material. Often, the client will display behaviour that is regarded as contradictory to adequate treatment progression, leading to interpretations about that person's motivation and utilisation of the treatment. In addition, such interpretations will sometimes lead to inferences about causality, stating that the lack of motivation and utilisation is due to individual 
characteristics. Then, to provide adequate help for the person, temporary adjustments and actions are made towards alternative treatment programmes elsewhere. From an ideological point of view, this position makes sense. Some clients may disturb important treatment processes for the institutional community and other clients, and it is crucial to take actions to prevent such problems, both to protect other clients and their treatment progression and important aspects of the treatment programme. From an individual point of view, however, this is a problematic issue. The treatment programme is at risk of turning rigid, without displaying the necessary abilities to adjust to the individual's treatment needs. In such cases, the risk of increased resistance is present, possibly attenuating the therapeutic alliance.

As mentioned above, issues of resistance and therapeutic alliance are important factors for how the client accepts the treatment, and they can also function as risk factors for those dropping out of treatment (Brorson et al., 2013). In making attributional errors like this, the critical focus is placed on the individual, not the features of the treatment. By not asking how to adjust the treatment to provide necessary help-and instead, attributing causality to an untreatable condition inside the individual that cannot be addressed by this particular treatment programme-this leads to possible rejection and admission into another treatment programme that is regarded as a better fit:

So it is about investigating what exists instead of, may another unit provide a better fit dependent on group size, gender, aspects of the treatment, or is it ... that the person cannot even be in a group treatment programme? Then this must be addressed together with the principles for the admission, and we see that these youth are unable to utilise the group treatment or the methods that we use mostly. This is a process that unfortunately often takes too long, especially in cases when we have youths under compulsory admission. Then it is extra challenging. 


\section{Cognitive Deficits and Treatment Methods}

In substance use treatment it is common among patients to have cognitive deficits(Brorson et al., 2013), and there are reasons to believe that there are many unrecorded cases (van Duijvenbode \& VanDerNagel, 2019). In some individuals, it might be difficult to assess whether cognitive deficits are caused by innate or acquired factors (e.g. substance abuse in early adolescents). However, the description of the individual's present situation is important regarding treatment. To the informants' knowledge, they had each worked with clients with cognitive deficits. One even stated, 'A lot of clients have cognitive deficits, and when you are able to detect it, you should adjust'. When asked in the interview, none of the informants had a clear answer regarding how to deal with these individuals. The lack of a plan was evident insofar as prevalent answers were to 'talk' to their superiors, co-workers and the individuals' peers. One informant emphasised sticking to the institution's form: 'Use the group, mirroring, mentalise, again and again and again. If they aren't too weak, they will eventually learn and correct themselves'. This informant also pointed out that it can be a tough culture in these groups, and when dealing with members who have cognitive deficits, they should be careful: 'We just have to adjust. Start with ourselves, then the adolescents, and hope it turns out fine'.

The examples above show a lack of consensus within institutions regarding how to address these clients as members in the group of collective treatment. Individual adjustments need to be made within the collective paradigm. The informants addressed limitations concerning these problems and possible solutions to them. However, it seems that the solutions are outside the collective treatment paradigm, as several informants stated that if they are not able to help clients within the paradigm, they have to 'think about what else is out there' or 'think of other solutions'. 
All the informants suggested mentalisation therapy as one of the key components of their treatment. Mentalisation is defined as a process of making sense of the subjective states and mental processes in others and the self, both psychologically and physically (Bateman \& Fonagy, 2010). Individuals with cognitive deficits may have impairments in various mental processes, such as attention, decision making, judgement, , planning and reasoning (Schofield, 2018). Hence, the processes that mentalisation therapy relies on may be beyond the range of some individuals with cognitive deficits, which leads back to the first theme regarding individual needs. Although we have addressed the individual needs versus treatment foundations, we think it is important to emphasise this paradox, which manifests when a treatment method that is based on mentalisation is used for people who may lack the ability to mentalise.

When addressing the topic of possible weaknesses concerning the use of mentalisation, the informants revealed a consensus that individuals with cognitive deficits do not always experience a favourable outcome. The informants addressed topics like misunderstanding and resistance towards the method and that these clients not necessarily benefit from the such techniques:

The ones with cognitive deficits do not always benefit from it, . . and it is unfortunate if they're too weak to fit in with a regular group of adolescents. Because it is a high temperature, and everything moves quickly [the informants use of the term "high temperature" we interpret as covering meanings of various emotional expressions (i.e resistance, agitation) displayed by participants due to group processes]

Another informant stated that, if the individual does not understand the premises, for example, why use groups and so forth, then the individual should not be there: 'In that case, it would almost be an abuse'. 


\section{Limitations}

This study had some limitations. First, the sample was small, and thus, as in all qualitative research, the findings may not be generalisable. Further, this study focussed on how treatment staff experience issues regarding the problem field of individualised treatment and community as method; hence, we did not interview clients receiving the treatment. Thus, our findings lack important information relating to the client's perspective. However, important issues/elements were mentioned by the participants, which indicates that there is reason to investigate these issues further. Another limitation is that, although interviews were read in random order, anchor or primacy effects (Mumma \& Wilson, 1995) from the first interview read may have biased the authors when analysing the rest of the interviews. A final possible weakness to mention here might relate to translational issues. None of the authors have English as their native language, and the translations of the informants' quotations should be read with this in mind.

\section{Summary and Conclusion}

Our aim was to explore the tensions between implementing the collective treatment model's emphasis on community as method and treating the needs of individuals enrolled in the treatment. Using a semi-structured interview procedure and analysing in a thematic order, we found indications that these tensions are present and that there are important issues to be further addressed.

Our study revealed the three following major themes: (a) individual treatment needs face possible neglect with strong adherence to the treatment programme enshrined in the institutional framework, (b) too rigid an interpretation of community as method may lead to attributional errors and possible rejection of 
the client and (c) a lack of consensus within the institutions concerning how to adjust to cognitive deficits within the collective paradigm. These themes illustrate important challenges that may occur when attempting to adequately adjust treatment for people with substance use disorders based on carefully and individually assessed needs. Moreover, our study addressed how the identified challenges may apply to treatment programmes that emphasise the community as method and adherence to the treatment programmes enshrined in the institutional framework. In our analysis, such challenges were present, and informants displayed a certain lack of consensus in how they described various issues concerning the obvious tension in the space between the collective paradigm and individual treatment needs. These tensions have important ethical aspects regarding the individual patient, as we have clarified in this paper, as well as ethical aspects regarding the collective group. As mentioned above, some patients will display disruptive behaviour within the institutional setting, representing challenges and possible danger to other clients' treatment processes. The ethical dilemma in these cases is complex. However, as discussed in this paper, we suggest that such ethical aspects should be explored from the individual point of view.

The central principle in the treatment of people with substance use disorders is the facilitation of treatment interventions based on careful assessment of the individual treatment needs. This also applies in cases where the client clearly disrupts own and others' treatment processes. In other words, careful ethical considerations should include that the collective group is a key component of the treatment programme and that individual treatment needs are not neglected to protect various treatment components or interventions. In cases where the client is admitted into another treatment facility that is considered better able to provide adequate treatment for that person, this should be a result of careful assessment from an individual point of view, ensuring that important treatment needs are safeguarded. Such processes should imply thorough considerations 
of important ethical aspects and aim to prevent unwanted rejection of the client due to attributional factors.

The importance of the therapeutic alliance is considered a key element in the treatment of people with substance use disorders, and this issue was also stated by our informants. However, the safeguarding of individual treatment needs will require flexibility in the adherence to the treatment programme, and such a lack of flexibility in adherence may face challenges regarding resistance in clients and possibly lead to therapeutic relationships that are antagonistic.

Our findings then suggest both important research questions to be further addressed and clinical implications. Such important research questions should, for example, focus on how to address and assess individual treatment needs and how to design adequate individualised treatment within such collective institutions. One particular research question to be addressed further should be focusing on how to apply adequate approaches and tailored treatment within the collective treatment setting for clients who have cognitive impairments. As presented in our study, consistency in how to meet such individuals' specific treatment needs and plans regarding this issue seems to be lacking and calls for further investigation. An important implication from a clinical perspective is how institutions should adapt to the increased emphasis on individualised treatment and adjust accordingly by demonstrating flexibility in their adherence to the treatment programme. 


\section{References}

Bateman, A., \& Fonagy, P. (2010). Mentalization based treatment for borderline personality disorder. World Psychiatry, 9(1), 11-15. https://dx.doi.org/10.1002\%2Fj.2051$\underline{5545.2010 . t b 00255 . x}$

Braun, V., \& Clarke, V. (2006). Using thematic analysis in psychology. Qualitative Research in Psychology, 3(2), 77-101. https://doi.org/10.1191/1478088706qp063oa

Brorson, H. H., Ajo Arnevik, E., Rand-Hendriksen, K., \& Duckert, F. (2013). Drop-out from addiction treatment: A systematic review of risk factors. Clinical Psychology Review, 33(8), 1010-1024. https://doi.org/10.1016/j.cpr.2013.07.007

Chen, G., Elisha, E., Timor, U., \& Ronel, N. (2015). Why do adolescents drop out of a therapeutic community for people with drug addiction? Journal of Child \& Adolescent Substance Abuse, 25(1), 65-77. https://doi.org/10.1080/1067828X.2014.918002

De Leon, G. (2000). The therapeutic community: Theory, model, and method. Springer Publishing. https://doi.org/10.1891/9780826116673

De Leon, G., \& Wexler, H. (2009). The therapeutic community for addictions: An evolving knowledge base. Journal of Drug Issues, 39(1), 167-177. https://doi.org/10.1177\%2F002204260903900113

Dye, M. H., Roman, P. M., Knudsen, H. K., \& Johnson, J. A. (2012). The availability of integrated care in a national sample of therapeutic communities. The Journal of Behavioral Health Services \& Research, 39(1), 17-27. https://doi.org/10.1007/s11414-011-9251-1

Helsedirektoratet. (2011). Nasjonal faglig retningslinje for utredning, behandling og oppfølging av personer med samtidig ruslidelse og psykisk lidelse-ROP-lidelser. https://www.helsedirektoratet.no/retningslinjer/samtidig-ruslidelse-og-psykisk-lidelse$\underline{\text { rop-lidelser }}$

Helsedirektoratet. (2017). Nasjonal faglig retningslinje for behandling og rehabilitering av rusmiddelproblemer og avhengighet. https://www.helsedirektoratet.no/retningslinjer/behandling-og-rehabilitering-avrusmiddelproblemer-og-avhengighet

Kolltveit, S., \& Lange-Nielsen, I. I. (2013). Behandlingselementer i ruskollektiver for ungdom. Tidsskrift for Norsk psykologforening, 50(9), 919-925.

Kristoffersen, C. H., Holth, P., \& Ogden, T. (2011). Modeller for Rusbehandling. En Kunnskapsoversikt. Atferdssenteret. http://www.forebygging.no/Global/110506\%20Modeller\%20for\%20rusbehandling $\% 20$ en\%20kunnskapsoversikt.pdf

Mumma, G. H., \& Wilson, S. B. (1995). Procedural debiasing of primacy/anchoring effects in clinical-like judgements. Journal of Clinical Psychology, 51(6), 841-853. https://doi.org/10.1002/1097-4679(199511)51:6\%3C841::AIDJCLP2270510617\%3E3.0.CO;2-K

National Institute on Drug Abuse. (2014). Principles of adolescent substance use disorder treatment: A research-based guide. https://www.drugabuse.gov/publications/principles-adolescent-substance-usedisorder-treatment-research-based-guide/principles-adolescent-substance-usedisorder-treatment

National Institute on Drug Abuse. (2015, July 23). What are Therapeutic Communities? https://www.drugabuse.gov/publications/research-reports/therapeutic-communities

Ness, O., Borg, M., \& Davidson, L. (2014). Facilitators and barriers in dual recovery: A literature review of first-person perspectives. Advances in Dual Diagnosis, 7(3), 107117. https://doi.org/10.1108/ADD-02-2014-0007 
Ose, O. O., \& Pettersen, I. (2014). Døgnpasienter i TSB 20. november 2012. Baseline for samhandlingsreformen. http://hdl.handle.net/11250/2505205

Ravndal, E. (2007). Evaluering av behandlingskollektiver i rusomsorgen: Har de fortsatt en plass i dagens rusbehandling? Tidsskrift for Norsk Psykologforening, 44(1), 17-21.

Ross, L. (1977). The intuitive psychologist and his shortcomings: distortions in the attribution process. In L. Berkowitz (Ed.), Advances in experimental social psychology (Vol. 10, pp. 173-220). Academic Press. https://doi.org/10.1016/S0065-2601(08)60357-3

Schofield, D. W. (2018, December 26). Cognitive deficits. Medscape. https://emedicine.medscape.com/article/917629-overview

Slade, M. (2009). 100 ways to support recovery. A guide for mental health professionals. Rethink Recovery Series.

https://recoverylibrary.unimelb.edu.au/ data/assets/pdf file/0005/1391270/100 way s to support recovery.pdf

Slade, M., Leamy, M., Bacon, F., Janosik, M., Le Boutillier, C., Williams, J., \& Bird, V. (2012). International differences in understanding recovery: Systematic review. Epidemiology and Psychiatric Sciences, 21(4), 353-364. https://doi.org/10.1017/S2045796012000133

Steiro, A., Dalsbø, T. K., Smedslund, G., Hammerstrøm, K. T., \& Samdal, K. (2009). Hva er effekten av langtidsbehandling $i$ institusjon for personer med rusavhengighet sammenlignet med poliklinisk korttidsbehandling? (Report no. 20-2009). Nasjonalt kunnskapssenter for helsetjenesten. https://www.fhi.no/publ/eldre/hva-er-effekten-avlangtidsbehandling-i-institusjon-for-rusavhengige-sammen/

van Duijvenbode, N. V., \& VanDerNagel, J. E. L. (2019). A systematic review of substance use (disorder) in individuals with mild to borderline intellectual disability. European Addiction Research, 25, 263-282. https://doi.org/10.1159/000501679

Wampold, B. E. (2015). How important are the common factors in psychotherapy? An update. World Psychiatry, 14(3), 270-277. https://doi.org/10.1002/wps.20238 